\title{
Students' Attention to Lectures: Examining the Influence of Self-Esteem and Locus of Control
}

\author{
Okoye, Chukwuemeka A.F. Ezeodina, Favour O. \\ Faculty of Social Sciences, Department of Psychology, Nnamdi Azikiwe University, P.M.B 5025, Awka. \\ Anambra State - Nigeria.
}

\begin{abstract}
Observation has revealed that while lecture is going on, rather than paying attention, students engage themselves in irrelevant activities like fiddling with their mobile phones, sneaking out of lecture halls and so on. This study investigated the influence of Self-esteem and Locus of control on attention to lectures among undergraduates of Mass Communication department, Nnamdi Azikiwe University, Awka. A sample size of 236 students were selected for the study from a population of 577 through simple random sampling method. The samples comprised of $04(44.1 \%)$ males and 132(55.9\%) females. Their age ranged from 17-32 years, with mean age of 22 and standard deviation of 2.86. Three scales were administered to the participants, which include Index of Self-Esteem by Hudson (1982), Locus of Control Internal- External scale by Rotter (1966), and Moss Attention Rating Scale by Whyte, Hart, Bode \& Male C(2003). Data were collected through survey method and was analyzed using descriptive statistics and two-way analysis of Variance. The study tested three hypotheses, the ANOVA statistics revealed a significant influence of students' self esteem on attention to Lectures $F(1,232)=$ 5.72, $\mathrm{P}<.05$, and a non-significant influence of Locus of control on attention to Lectures $\mathrm{F}(1,232)=1.01, \mathrm{P}>.05$. These was a non-significant interaction effect of Self-esteem and Locus of control on attention to Lectures $\mathrm{F}(1,232)=.04, \mathrm{P}>.05$. Based on the descriptive analysis, it was observed that students who scored high in their Self-esteem measures paid more attention to lectures than those who scored low. The researchers, among others, recommends that lecturers in tertiary institutions should employ teaching methods that will enhance students' Self-esteem during learning.
\end{abstract}

Keywords: Self-esteem, Locus, Control, Attention, Lectures.

DOI: $10.7176 / \mathrm{RHSS} / 9-16-03$

Publication date: August $31^{\text {st }} 2019$

\section{Introduction}

In the classroom setting, common expectation demands that students should demonstrate a good deal of attention to the on-going lectures. Observations revealed that while lectures are going on, rather than paying attention, students engage themselves in irrelevant activities, which do manifest in behaviours such as busying themselves with their phones or laptops. They can be seen making calls or texting, snapping photos, watching movies or pictures, chatting on social media like whatsapp, facebook; some are seen sneaking out of lecture hall, nodding off or gazing distractedly at some point other than the front of the class, among other unwholesome behaviours. This lack of attention is a problem that lecturers often find very challenging.

Attention remains a major area of investigation in the field of psychology, education, neuroscience, cognitive neuro-science and neuropsychology. Accordingly, Science Daily (2013), defined attention as the cognitive process of selectively concentrating on one thing while ignoring other things. In the views of Cherry (2013), attention is when an individual tunes out irrelevant information, perceptions, and sensations at any moment and focus on the energy of importance. Anderson (2004), also defined attention as the behavioural and cognitive process of selectively concentrating on a separate aspect of information, whether deemed subjective or objective, while ignoring perceivable information. Types of attention include voluntary and involuntary attention amongst others.

Indeed, inability of students to pay attention during lectures has become a trend. Bunce, Flens \& Neiles (2010), confirmed in a research that students are more engaged and attentive when they are doing something other than listening to lectures. The symptoms associated with this lack of attention include difficulty in remaining focus during lectures, failure to listen to details, careless mistakes in school works, mind wandering during lectures, unable to follow instructions, failure to meet deadlines, poor time management, easily distracted by extraneous stimuli during lectures, amongst others The perceived consequences include poor academic grades, school dropouts, examination misconducts, academic procrastination, delinquency, aggressive behaviour, gang membership, substance abuse, promiscuity and so. Following these consequences, Marks, Newcorn \& Halperin (2001), noted that Attention Deficit Hyperactivity Disorder (ADHD) in adults is accompanied by an increased risk of substance abuse, anxiety and mood disorders.

Considering the foregoing, psychologist and social scientists would want to understand the effects of other variables on attention to lectures such as intelligent, consciousness, personality, time, fatigue, stress, learning styles, anxiety aroused, cognition, self-concept, self-efficacy, depression, achievement motivation, expectancy, 
duration of lectures, multiple academic lasting, cultural variation, to mention but a few.

Studies have reported the existence of significant relationship between self-esteem and academic achievement. For example, Muriana and Oyadeyi (2014) reported in a study that self-esteem predicted students' academic achievement. In the same vein, Onyekuru and Ibegbunam (2014), equally found that a significant positive relationship exists between internal locus of control and students' academic achievement, while there was no significant relationship between external locus of control and students' academic achievement. Therefore, it could be suspected that self-esteem and locus of control just like other variables mentioned above, might have influence on the manner in which students pay attention to lectures.

Smith and Mackie (2007), defined self-esteem as the positive or negative evaluations of the self. Also, Garry (2007) notes that self-esteem is the evaluation, which an individual makes about his or her own worth, competence and significance. Garry further suggests that when one gives a positive opinion of oneself like competence, confidence or understanding, the person has high self-esteem. On the contrary, when one gives a negative opinion of oneself like incompetence, unworthy, worthless or inferior, the person has low self-esteem.

Locus of control is the degree to which people believe that they have control over the outcome of events in their lives, as opposed to external forces beyond their control. Kirkpatrick, Stant, Downes \& Gaither (2008), defined Locus of control the degree to which individuals perceive reinforcing events in their lives to be the result of their own actions or fate. Rother (1954), also saw Locus of control as the tendency of people to believe that control resides internally within them, or externally, with others or the situation. Rotter categorized between external and internal locus of control given the possible links, this study examined the influence of Self-esteem and locus of control on attention to lectures among undergraduates.

Theoretically, various perspectives have been adduced to explain the concept of attention Fleming (2014), proposed the VARK Learning model designed to help students and other learners understand individual learning preferences. VARK is an acronym for V-visual, A-Auditory, R-Read/write and K-Kinesthetic. Thus, Fleming developed four learning models as (1) visual learning (ii) Auditory learning (iii) Read/write learning and (iv) Kinesthetic learning. He maintained that visual learners have a preference for seeing visual aids that represent ideas using methods other than words such as graphs charts, diagrams, symbols; among others. Auditory learners learn best through listening. They learn better through lectures, discussions, tapes, group study and the like. Read/write learners prefer information display as words. They re-write notes read/review notes every day, turn charts and diagram into words and make lists. For Tactile/Kinesthic learners, they prefer learning through experience-moving, touching, doing active exploration of world and experiments indeed students can use this model to identify their preferred learning style and it is claimed that it maximizes learning by focusing on the mode that benefits students the most. Based on this theory, it could be implied that students who do not prefer the available learning modality may not find the lecture interesting and thus may not pay attention; On the contrary, students who prefer the available learning modality may find the lecture interesting and thus pay attention. For instance, students who prefer auditory modality may miss out when a lesson plan is being projected while visual learners may follow up satisfactorily.

Another theory that tried explaining attention in the cognitive Load theory by Sweller (1988). The theory stated that there are two mechanisms that affect attention: cognitive and perceptual. The perceptual considers the subject's ability to perceive or ignore stimuli, both task related and non-task-related. If there are many stimuli present (especially if they are task-related), it is much easier to ignore the non-task related stimuli, but if there are few stimuli the mind will perceive the irrelevant stimuli as well as the relevant. The cognitive refers to the actual processing of the stimuli. The ability to process stimuli decrease with age. That is, younger people could perceive and fully process more stimuli, but were likely to process both relevant and irrelevant information, while older people could process fewer stimuli, but usually processed only relevant information.

Following this theory, in terms of perceptual; since there are few stimuli (ie the lecturer and probably the board), students mind may drift towards both relevant and irrelevant stimuli. That is, they may tend to divide their attention between the Lecture (relevant stimuli) and other irrelevant activities like busying with their mobiles. In terms of cognitive, students (which are younger persons tend to always process both relevant and irrelevant information, unlike older people, who will process only relevant information. Based on this theory, it could be concluded that students' attention to lectures may not always be stable except for some personality attributes (like self-esteem, Locus of control, self-concept, e.t.c).

Empirical studies have also been undertaken by scholars on the relationship between some variables and attention to academic activities. Evans and Julius (2015), studied the relationship between study habits and academic achievement of students in Spicer Higher Secondary School India. The study habits connote budgeting time, reading ability, note taking, learning motivation and preparation for examination. The study determined the relationship between study habits and academic achievement, employing a survey study and descriptive correlational design. The participant were 104 students of $9^{\text {th }}$ Standard in the academic Year 2009-10. Study Habit inventory by Palsane (1977), and school examinations records were the instruments for data generation. Pearson product moment coefficient was used to analyze the data. The result revealed a positive relationship 
between study habits and academic achievement.

Erik and Jackson (2013), carried out a study on capturing students' attention to investigate the influence of external stimulus on students' attention. The study was a randomized experimental design involving 846 students over a four-year period in a general education classroom at a large, urban university. The participants were randomly assigned to either an arousal (experimental) or no-arousal (control) group. The experimental group was exposed to a topic-relevant, 90-second external stimulus (a technique used to elevate arousal and focus attention). The control group listened to the instructor take roll call. Both groups then listened to the same 30-mnutes lecture followed by an examination. Two instruments were used for the study. The first instrument was a performance score on a 15-point examination with a minimum score of 9 and a maximum score of 15, which was used to measure the dependent variable (i.e information retention). The second instrument measured instructor enthusiasm on a 7-point scale. An independent samples t-test was used for data analysis. The result indicated that students exposed to external stimulus (i.e poem, game, puzzle) before a 30-minute lecture demonstrated significantly better information retention than students exposed to a neutral stimulus. The study revealed that exposing students to external stimulus enhances their attention to lecture.

In the same vein, Bunce, Flens, \& Neiles (2010), conducted a study of inattention in three different chemistry courses. Students in those courses used clickers to self-report Lapses in their attention to the research team, not the course teacher. After each Lapse, students pressed one of the three buttons indicated a lapse of a minute or less, the second button indicated lapses of two or three minutes, and a third button indicated lapses of five minutes or longer. A fairly complex set of methods was used to analyze the attention lapses and compare them with what was happening in class at the time. The result confirmed that students are more engaged and attentive when they are doing something other than listening to the teacher's lecture. This study revealed that students pay less attention to lecture and pay more attention to activities outside lecture or learning settings.

Muraina and Oyedeyi (2014), conducted a study on academic efficacy and self-esteem as predictors of academic achievement among school- going adolescents in Itesiwaju Local Government area of Oyo state, Nigeria. The purpose of the study was to investigate whether academic efficacy and self-esteem could predict academic achievement, 300 participants which were selected from 30 secondary schools through stratified random sampling took part in the study. Three instruments were also used: Academic Efficiency Scale by Chemers (2001), Self-Esteem Scale by Rosenberg (1993), and Student Achievement Scale, which was developed based on the present scheme of secondary school student one (sss1) with Cronbach alpha coefficient of 0.73 . The data was analyzed using the Pearson Product Moment correlation. The result showed that academic efficacy and self-esteem jointly predicted students' academic achievement. The result therefore showed that self-esteem predicted students' academic achievement. This means that self-esteem may influence students' attention to lectures.

Onykuru and Ibegbunam (2014), carried out a study that investigated the relationship between test anxiety, Locus of control and Academic achievement among undergraduates. 364 students volunteered to participate in the study from a population of 498 students in the departments of curriculum studies and Educational technology, University of Port-Harcourt, Nigeria for 2009/2010 and 2010/2011 academic session. The study adopted a longitudinal design and the data generated were analyzed using Pearson Product Moment Correlation. The result showed a weak, but significant negative relationship between test anxiety and students' academic achievement. A significant positive relationship was also found between internal Locus of control and students' academic achievement. Finally, relationship between external locus of control and students' academic achievement did not show any significant correlation.

Abel and Moyosola (2013), conducted a study that examined the influence of academic self-efficacy, locus of control and academic performance of secondary school students in Ondo state, Nigeria. 364 students' who were randomly selected from 10 schools participated in the study. They were administered self - in school scale by Andrews (1984) to assess levels of academic self-efficacy and locus of control respectively. The students' score in their previous promotion exam were used to measure academic performance. The researchers found that academic self-efficacy predicted academic performance while locus of control was not a good predictor.

\section{Statement of the Problem}

Nowadays, during classroom learning, students prefer to either divide their attention or shift it completely from the on-going lecture. Students are usually seen performing activities that are considered extraneous to the lecture situation, rather than listening to the lecture. They are usually seen sneaking out of the lecture hall, browsing the net, playing games with their smart phones, making advances to their opposite sex, chatting on social media, and so on. If this trend continues unchecked, chances are that we would experience a fall in the standard of education as will be evidenced by the quality of graduates that will be produced over time.

Moreover, empirical studies revealed that self-esteem and locus of control have not been extensively studied in relation to attention to lectures among undergraduates. Past studies on self-esteem and locus of control of students had focused mainly on academic performance and achievement motivation. Therefore, this study 
investigated the influence of self-esteem and locus of control on attention to lecture among Nigeria undergraduates.

From the foregoing, the following research Questions guided the study.

1. Would there be a significant difference between students who scored high and those who scored low on self-esteem measures in their attention to lectures to lectures?

2. Would there be a significant difference between students who are externally controlled and those who are internally controlled in their attention to lectures?

3. Would there be a significant interaction effect between self-esteem and locus of control of students in their attention to lectures?

The major purpose of the study was to investigate the influence of self-esteem and locus of control on attention to lectures among undergraduate of Nnamdi Azikiwe University, Awka, Nigeria.

However, the specific objectives of the study are:

1. To investigate whether a significant difference exists between self-esteem and attention to lectures.

2. To investigate whether a significant difference exists between locus of control and attention to lectures.

3. To investigate whether a significant interaction effect exists between self-esteem and locus of control on attention to lectures.

\subsection{Hypotheses}

1. There will be a significant difference between students who scored high and those who scored low on self-esteem measures in their attention to lectures.

2. There will be a significant difference between students who are externally controlled and those who are internally controlled in their attention to lectures.

3. There will be a significant interaction effect between self-esteem and locus of control of students in their attention to lectures.

\subsection{Method}

\section{Participants}

Two hundred and thirty-six (236) participants were selected and participated in the study. The ages ranged from 17-32 years, with a mean age of 22.0 and standard deviation of 2.86 . Out of the 236 participants, one hundred and four (104) (44.1\%) were males while one hundred and thirty-two (132) (55.9\%) were females.

\section{Instruments}

Three scales were used: Index of Self-Esteem (Hundson, 1982), Locus of Control Scale (Rotter, 1966) and Moss Attention Rating Scale (MARS) (MOSS, 2003). All the scales have satisfactory validity and reliability status; particularly in the area of face, content divergent validity. Also, their rehabilitee coefficients were confirmed.

\section{Procedure}

The three instruments were arranged in a continuous format and administered to the participants in their classrooms. They were requested to fill and complete the questionnaire in the presence of the researchers. Altogether, 320 questionnaires were distributed among the participants. After the collection of the questionnaire, 236 were found to have been properly filled and were later analyzed.

\section{Design/Statistics}

The study in survey, that adopted a $2 \times 2$ factorial design (two independent level with two levels each over one dependent variable). The statistics employed for data analysis were descriptive statistic and two- way Analysis of Variance.

\section{Result}

Table 1: Summary table of mean and standard deviation for self-esteem, Locus of control and Attention to lectures among students.

\begin{tabular}{|lccc|}
\hline & Mean $(\mathrm{x})$ & SD & N . \\
\hline Self-Esteem & & & \\
High & 71.27 & 7.44 & 125 \\
Low & 69.09 & 6.59 & 111 \\
Total & 70.18 & 7.02 & 236 \\
Locus of Control & & & \\
External & 69.83 & 7.60 & 121 \\
Internal & 70.68 & 6.59 & 236 \\
Total & 70.26 & 7.09 & 115 \\
\hline
\end{tabular}

Result in the table above showed that participants who have high self-esteem $(\mathrm{x}=71.27 ; \mathrm{SD}=7.44)$ scored higher than those who have low self-esteem $(x=69.09$; SD 6.59) On the other hand participants who are externally controlled $(x=69.83 ; \mathrm{SD}=7.60)$ scored slightly higher than those who are internally controlled $(x=$ 
70.68; $\mathrm{SD}=6.39$ ).

Table 2. Summary table of Two-way ANOVA on self-esteem, Locus of Control and attention to lectures among undergraduates.

\begin{tabular}{|c|c|c|c|c|c|}
\hline Source & SS & $\mathrm{df}$ & Ms & $\mathrm{F}$ & Sig \\
\hline Self-esteem(SE) & 286.08 & 1 & 286.08 & 5.72 & .018 \\
\hline Locus of Control (LOC) & 50.36 & 1 & 50.36 & 1.01 & .317 \\
\hline $\mathrm{SE} * \mathrm{LOC}$ & 2.12 & 1 & 2.12 & .04 & .838 \\
\hline Error & 11600.41 & 232 & 50.00 & & \\
\hline Total & 1176466.00 & 236 & & & \\
\hline Corrected Total & 11931.75 & 235 & & & \\
\hline
\end{tabular}

a. $\quad$ R Square $=.028$ (Adjusted R Square $=.015$.

The result above showed that there was a significant main effect of self esteem on attention to lectures' Hypothesis 1 , was accepted at $(\mathrm{F}=5.72 ; \mathrm{P}<.02$. Also, there was a non - significant main effect of Locus of control on attention to lectures. Hypothesis 2 , was rejected at $(\mathrm{F}=1.01 ; \mathrm{P}<.32$. Furthermore, there was nonsignificant interaction effect between self-esteem and Locus of Control on students' attention to lectures. Hypothesis 3 was rejected at $(\mathrm{F}=.04 ; \mathrm{P}<.84)$.

\section{Discussion and Conclusion}

The result of the first hypothesis showed that there was a significant difference between students who scored high and those who scored low in their self-esteem measure on their attention to lectures. This means that students with high self-esteem differ from those with low self-esteem on the manner in which they pay attention to lectures. This finding is in agreement with previous studies by Muraina and Oyadeyi (2014), who found that self-esteem is a predictor of academic achievement. This implies that self-esteem equally influenced students' attention to lectures. This is because in an ideal situation students' who paid attention to lectures are more likely to record high academic performance and or achievement than those who did not. Thus, if self-esteem influenced students' academic achievement, it is also likely to influence their attention to lectures'.

The result of the second hypothesis revealed that there was no significant difference between students who are externally controlled and those who are internally controlled on their attention to lectures. This means that both students who are externally controlled and those who are internally controlled do not differ in the manner in which they pay attention to lectures. Therefore, the hypothesis 2 was rejected This result is in line with the finding of Abel and Moyosola (2013) who found that academic self-efficacy predicted academic performance while locus of control did not. Therefore, it can be said that locus of control did not have influence on students' attention to lectures. This is because, learning experience is also a factor that can determine whether a student will pay attention to a particular lecture or not. For example, if a student perceives a particular course as being an easy one, she may not pay attention or may not even attend the lecture. Again, attention to lectures can greatly influence students' academic performance.

In the same vein, the result of the third hypothesis revealed that there was no significant interaction effect between self-esteem and locus of control of students on their attention to lectures. This means that self-esteem and locus of control together did not influence the manner in which students pay attention to lectures.

\section{Implication of the Study}

This study has created awareness on the influence of self-esteem and locus of control on attention to lectures among undergraduates. The findings revealed that the higher the self-esteem of undergraduates the more they pay attention to lectures and vice versa. Therefore, proper measures (such as incentives, rewards, warmth creation, e.t.cetra) should be taken during lectures in order to boost students' self-esteem. This will enable students' width low self-esteem to benefit.

The findings also revealed that locus of control did not have influence on students' attention to lectures. Therefore, much emphasis may not be necessarily needed on how to control students' locus of control during lectures.

Conclusively, it was observed that during classroom learning, students do not normally pay attention to lectures. They always prefer to engage themselves in other activities that are considered extraneous to learning setting such as busying with their phones. Therefore, this study examined whether (self-esteem and locus of control were contributory factors that influence attention to lectures among undergraduates. The findings revealed that self-esteem had a significant influence on attention to lectures while locus of control had not. It can then be concluded that high level of self-esteem leads to attentiveness during lectures while locus of control (whether internal or external) did not. Emphasis on improving self-esteem of undergraduates should be taken into consideration across learning settings.

Deriving from the foregoing, the researchers therefore recommends the following:

1. Lecturers and other tutors in tertiary institutions should be aware that self-esteem plays an important 
role on students' attention to lectures. They should thus, employ teaching strategies that will enhance their students' attention during lectures' They can use incentives and rewards to achieve this.

2. Authorities in tertiary institutions should also develop intermittent programmes through which students' self-esteem can be improved.

3. Again, parents should be encouraged to provide care and support for their children and wards because this will go a long way to ensure better adjustment in students' self-esteem later in life.

4. In addition, there are very few scales available for measuring attention related behaviours. Thus, researchers are encouraged to develop more indigenous scales for this constract in order to make them readily available for upcoming researchers and to improve professional competency.

\section{References}

Abel, o.o; \& Moyosola J.A. (2013). Academic Self-Efficacy, Locus of Control and Academic Performance of Secondary School Student in Ondo state, Nigeria. Mediterranean Journal of Social Sciences. MCSER Publishing, Rome-Italy, Vol.4 No 11.

Anderson, R-(2004). Cognitive psychology and its implications ( $6^{\text {th }}$ Ed). Worth Publishing. London.

Bunce, D.M; Flens, E.A; \& Neiles, K.Y. (2010). How long can students pay attention in class? A study of attention decline using clicker. Journal of Chemical Education, 87(12),1438-1443.

Cherry, K. (2013). About.com: $\quad$ Psychology $\quad$ Retrieved from http:llpsychology.about.com/od/cognitivepsychology/f/attention.html.

Erik, R; \& Jackson, W. (2013). Capturing students' attention. An empirical study. Journal of the scholarship of Teaching and Learning, 13(5), 1-20.

Evans, A.S; \& Julius, K. M. (2015). Study of the relationship between study habits and academic achievements of students: A case of Spicer Higher Secondary School India. International Journal of Educational Administration and Policy Studies, 7(7), 134-141.

Flening, N.D. (2014). "The VARK Modalities". Vark-Learn.com. Archived from the original on 14, March, 2015. Retrieved 9 August, 2015.

Garry, R.C. (2007). Christian Counseling. U.S.A. Zondervan Publishing House.

Hudson, N. (1982). Index of Self-Esteem. The clinical measurement package: A field manual. Chikago, Dorsey Press.

Kirkpatrick, M.A; Stant, K; Downs, S; \& Gaither, L. (2008). Perceived locus of control and Academic Performance: Broadening the Constructs Applicability, Journal of College Students Development, 49 (5), 486-496.

Marks, D.J; New corn, J.H; \& Halperin, J.M.(2001). Comorbidity in adults with attention-deficit hyperactivity disorder. In Jl Wasserstein, L.E. Wolf and F.F. Le Fever (Eds) Adult attention deficit disorder- Brain mechanisms and life outcomes. Pp. 216-238. New York Academy of Sciences.

Muriana, K.O; \& Oyadeyi, B.J. (2014). Academic Efficacy and Self-Esteem as Predictors of Academic Achievement among School Going Adolescents in Itesiwaju Local Government Area of Oyo State, Nigeria, Journal of Eucation and Practice, (6) 1, 6-12.

Onyekuru, U.B; \& Ibegbunam, J.O. (2014). Relationship Between Test Anxiety, Locus of Control and Aademic Achievement among College Students. European Scientific Journal, 10(13).

Rotter, J.B. (1966). Generalized expectancies for internal versus external control of reinforcement. Psychological monographs. General and Applied, 80, 1-28

Rotter, J.B. (1954). Social Learning and Clinical Psychology, NY: Prentice-Hall.

Rosenberg, M. (1993). Society and the Adolescent Self-Image. Princeton, NJ: Princeton University Press.

Science Daily (2013). Retrieved from http//www.sciencedaily.com/articles/a/.

Smith, E.R; \& Mackie, D.M. (2007). Social Psychology ( $3^{\text {rd }}$ Ed). Hove Psychology Press.

Sweller, J. (1988). Cognitive Load Theory During Problem-Solving. Effects on Learning cognitive science, 12(2) 257-285

Whyte, J; Hart T; Bode, R.K; \& Malae, J.F. (2003). The Moss Attention Rating Scale for Traumatic Brain Injury: Initial Psychometric Assessment. Archives Phys. Med. Rehabil, 84, 268-76. 